\title{
Online in No Time: Design and Implementation of a Remote Learning First Quarter General Chemistry Laboratory and Second Quarter Organic Chemistry Laboratory
}

5 William J. Howitz, ${ }^{\ddagger}$ Taylor A. Thane, $¥$ Taylor L. Frey, $\ddagger$ Xinran S. Wang, $¥$ Joe C. Gonzales, Chase A.

Tretbar, Daniel D. Seith, Shannon J. Saluga, Simon Lam, Melanie M. Nguyen, Peter Tieu, Renée D.

Link \& Kimberly D. Edwards*

Department of Chemistry, University of California-Irvine, Irvine, CA 92697, United States

\section{ABSTRACT}

The instruction of high enrollment general and organic chemistry laboratories at a large public university always have curricular, administrative, and logistical challenges. Herein, we describe how we met these challenges in the transition to remote teaching during the COVID-19 pandemic. We discuss the reasoning behind our approach, the utilization of our existing web-based course content, the additions and alterations to our curriculum, replacement of experimental work with videos, the future.

GRAPHICAL ABSTRACT

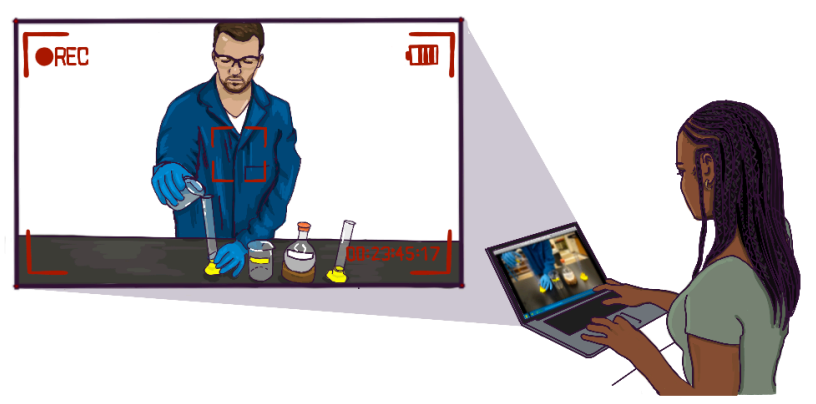

\section{KEYWORDS}

First-Year Undergraduate / General, Laboratory Instruction, Curriculum, Distance Learning / Self Instruction, Internet / Web-Based Learning, Multimedia-Based Learning 


\section{INTRODUCTION}

The onset of the global COVID-19 pandemic forced chemistry laboratory courses to rapidly shift from hands-on, experiential learning courses to remotely delivered courses. ${ }^{1}$ For the lower division laboratory courses at the University of California, Irvine (UCI), this emergency pivot to remote instruction occurred at the end of our winter term, requiring us to create a full quarter of chemistry laboratory courses for more than one thousand students in two weeks. Unlike schools on semester terms where instructors and students already had an established relationship, the students in our largest laboratory course (general chemistry) began their laboratory experience in this new remote format. We leveraged our existing course infrastructures, including extensive online tools, to create remote learning experiences as similar to our hands-on courses as possible. Both courses took very similar approaches, deviating only where needed to account for differing student needs.

\section{In-Person Course Structure}

$\mathrm{UCI}$ is a quarter-system school with three, 10-week terms per academic year. Chemistry laboratory courses for non-chemistry majors at UCI are offered in quarters offset from lecture courses (Table 1). ${ }^{2}$ The total approximate enrollment for these laboratory courses is 1,400 students for General Chemistry Lab I (GCL-I) and 1,000 students for Organic Chemistry Laboratory II (OCL-II). These students are spread across laboratory sections consisting of 20-24 students supervised by graduate student teaching assistants (TAs). Students attend their assigned laboratory section for a single 3 hour 50 minute session each week in the first eight weeks of the term and laboratory practical exams are given in the last two weeks of the term. The general chemistry laboratory courses contain weekly instructor lecture videos but no in-person lecture component. In contrast, the organic chemistry laboratory courses include both prelaboratory lecture videos and a 50-minute weekly interactive laboratory lecture taught by the instructor and offered in multiple sections of approximately 200-400 students. 
Table 1: Structure of General and Organic Chemistry Courses

\begin{tabular}{|c|c|c|c|}
\hline Year & Fall Quarter & Winter Quarter & Spring Quarter \\
\hline \multirow{3}{*}{ First Year } & $\begin{array}{l}\text { General Chemistry } \\
\text { Lecture I }\end{array}$ & $\begin{array}{l}\text { General Chemistry Lecture } \\
\text { II }\end{array}$ & $\begin{array}{l}\text { General Chemistry Lecture } \\
\text { III }\end{array}$ \\
\hline & No laboratory course & No laboratory course & $\begin{array}{l}\text { General Chemistry } \\
\text { Laboratory I (GCL-I) }\end{array}$ \\
\hline & $\begin{array}{l}\text { Organic Chemistry } \\
\text { Lecture I }\end{array}$ & $\begin{array}{l}\text { Organic Chemistry Lecture } \\
\text { II }\end{array}$ & $\begin{array}{l}\text { Organic Chemistry Lecture } \\
\text { III }\end{array}$ \\
\hline Second Year & $\begin{array}{l}\text { General Chemistry } \\
\text { Laboratory II }\end{array}$ & $\begin{array}{l}\text { Organic Chemistry } \\
\text { Laboratory I }\end{array}$ & $\begin{array}{l}\text { Organic Chemistry } \\
\text { Laboratory II (OCL-II) }\end{array}$ \\
\hline
\end{tabular}

GCL-I is the first college laboratory course taken by undergraduate science majors, primarily from biological sciences, public health, pharmaceutical sciences, and engineering. For undergraduate students, the first laboratory course can be a difficult transition as this may be their first experience with four-hour laboratory sections, electronic laboratory notebooks (ELNs), new laboratory techniques, and weekly reports. The large enrollment of these inexperienced students is challenging under normal circumstances. In a remote environment where instructional content was developed and implemented right before use, a large instructional team of seven development TAs and three learning assistants (LAs) was needed in addition to the 28 section TAs that would normally be assigned to the course. The development TAs supported the instructor by developing course material, while the LAs provided additional support for students through message boards and office hours.

OCL-II is the last chemistry laboratory course many students complete, typically at the end of their second year. They have already completed three chemistry laboratory courses and are familiar with the rigor, course policies, and technology requirements. Students enrolled in this laboratory course are also familiar with the instructor from a previous laboratory course experience. While the enrollment for this course typically approaches 1,000 students, a smaller offering with only 104 students was required in this scenario because the instructor (RDL) was also supporting colleagues who were 
converting organic chemistry lecture courses into an emergency remote format. A smaller instructional team of five development TAs and four instructional TAs was needed for this course.

\section{Laboratory Course Objectives and Existing Online Infrastructure}

In designing our emergency remote delivery course structures, we focused on maintaining as many

of our existing course objectives as possible (Table 2). The objective of students performing techniques

with chemicals, glassware, equipment, and instrumentation could not be achieved.3,4 Therefore, we

focused on other objectives typically assessed throughout a laboratory course by laboratory reports and during laboratory final exams: data interpretation and calculation, theory behind experiments, conceptual understanding of techniques / procedures, and laboratory safety. ${ }^{5}$

\section{Table 2. Course learning objectives for general and organic chemistry laboratory courses}

\section{General Chemistry Laboratory Organic Chemistry Laboratory}

1. Prepare solutions using volumetric glassware and calculate solution concentration. Use burette to perform titrations. Demonstrate understanding of the procedures and calculations associated with these techniques.

2. Operate temperature, conductivity and voltage probes, a simple visible spectrometer, and digital balance to acquire data.

*3. Proficiently use an electronic laboratory notebook to record qualitative observations in detail and quantitative data with the correct number of significant figures.

*4. Interpret experimental data and calculate results to develop scientifically sound conclusions.

*5. Employ basic computational chemistry to explain resonance, acid strength, and reaction coordinate diagrams.

*6. Demonstrate understanding of basic safety symbols, safety data sheets, corrosives, handling of chemical waste, fire safety, and chemical spill response.
1. Perform fundamental organic chemistry techniques in the context of laboratory experiments.

*2. Demonstrate understanding of concepts underlying fundamental techniques by proposing solutions to actual or potential problems encountered during an experiment.

*3. Accurately draw reaction mechanisms for reactions conducted in laboratory sessions.

*4. Use spectroscopy data to determine structures of unknown molecules.

*5. Use data collected from an experiment to make claims supported by evidence.

*6. Identify safe and unsafe practices related to techniques used in laboratory sessions.

\footnotetext{
*Course learning objectives prioritized in designing the remote delivery format.
} 
We were fortunate that our courses were well positioned for the remote environment because we

had already built the necessary internet-accessible framework of curriculum and instructional tools. ${ }^{6}$ Manuals, technique videos, readings, and instructor videos were already embedded in the ELN, LabArchives, and/or the learning management system, Canvas. ${ }^{7-22}$ Prelaboratory work consisted of online homework and completion of select portions of the ELN.10,13,23,24 During the laboratory session, students also utilized the ELN to enter procedures, observations, and data. Rubrics for grading on Canvas were already built, and Gradescope, an assignment submission and grading platform, had been used for laboratory practical exam grading for two years. ${ }^{25}$ Additionally, we had an existing means of communication with students through the message board, Piazza. ${ }^{13,26-29}$ Finally, we recognized we could compile authentic experimental data from the student ELNs of previous iterations of the courses.

Determining Our Emergency Pivot Approach

When converting our courses to a remote delivery format, both instructional teams were guided by principles grounded in the existing chemistry and STEM education literature. Courses were designed in a highly structured format to provide students with accountability for asynchronous coursework and regular formative assessments. ${ }^{30-37}$ A combination of asynchronous work and synchronous meetings were included to provide students with a connection to the instructor and TAs while also accommodating their rapidly changing schedules. ${ }^{38-41}$ We aimed to keep the course workload similar to the previous course format (or lighter if possible) for students and TAs.

In considering the best approach to transition our courses into an online format, we evaluated known replacements for experimental work. While simulations exist for general chemistry laboratory courses, we determined that we could not develop a rich online framework around such simulations comparable to the existing curriculum of GCL-I. Furthermore, we could not find simulations to cover half of the topics within GCL-I. Vendor-supplied kits for home experiments were not considered because of their cost and the lead time required to customize kits. ${ }^{42}$ Far fewer resources exist for virtual organic chemistry laboratories. The resources that do exist focus mainly on introducing laboratory techniques typically covered in a first-term course ${ }^{43}$ or incorporate verification experiments at odds with our standard curriculum. ${ }^{44}$ For both courses, we felt that the instructional tools present 
in our current electronic course content (i.e., lecture videos, online homework, computational studies)

were essential for student understanding of the content of whatever modality we chose to replace in-

lab experimentation. ${ }^{6}$ We also felt that developing supporting curriculum and summative assessments

for new content would add significant effort to an already challenging quarter. We concluded the more

expedient and pedagogically appropriate choice was to film experiments and use previously obtained

data for both laboratory courses. ${ }^{18-20}$ Access to a public Google Drive folder containing our

instructional materials and experiment videos is available in the Supporting Information.

\section{Table 3. Descriptive Summaries of GCL-I \& OCL-II}

GCL-I Experiments

1. Enthalpy of Formation:

Coffee cup calorimetry and Hess' Law used to find the enthalpy of reaction.

\section{Equilibrium and Visible Spectroscopy:}

The iron thiocyanate equilibrium constant is found using visible spectroscopy and LeChatelier's principle.

3. Computational Study of the Thiocyanate Ion: Spartan is used to investigate the actual structure of thiocyanate by looking at bond lengths and orbitals. Diatomic molecular orbitals are determined in the process

\section{Dissolution Thermodynamics:}

The enthalpy and entropy change for the dissolution of borax is determined by acid-base titration of borate ion samples taken at different temperatures.
OCL-II Experiments

1. Clove Oil Steam Distillation:

Eugenol is distilled from cloves. Purity is assessed by TLC and ${ }^{1} \mathrm{H}$ NMR.

2. Electrophilic Aromatic Substitution:

Relative reactivities determined by bromination of aromatic rings bearing various substituents.

\section{Wittig:}

Each lab section selects a variable to explore (Wittig salt, aldehyde, or base) from a list of available chemicals. The focus is on how the selected variable might affect the $E / Z$ selectivity of the products. Students run proposed reactions during the second week of the experiment. ${ }^{1} \mathrm{H}$ NMR analysis of all products within a lab section are shared to all students in that section. Students identify any trend present and address how this trend corresponds with their initial hypothesis.

\section{Oxidation and Reduction:}

Oxidation of 4-t-butylcyclohexanol to 4-tbutylcyclohexanone. Reductions of 4-tbutylcyclohexanone to 4-t-butylcyclohexanol using sodium borohydride and Meerwein-PondorffVerley conditions. ${ }^{1} \mathrm{H}$ NMR spectroscopy of resulting product mixtures. Spectra for product mixture resulting from reduction using Lselectride provided. Analysis requires explaining the differences in product mixtures under three different sets of reduction conditions. Help with analysis is provided in video and in person during lab lecture. 
5. Electrical Conduction of Solutions:

The conduction of various electrolytes is measured as a function of increasing atomic mass, acid strength, and increasing concentration. The equivalence point of a double displacement reaction is determined by conductometric titration.

\section{Acid-Base Buffers:}

Preparation and the investigation of the effects of acid or base addition and buffer dilution on $\mathrm{pH}$. Spartan investigation of dissociation as a function of acid strength.

\section{Electrochemical Cells:}

Measurement of cell potentials, creation of reduction potential table, and investigation of the effect of concentration on cell potential.
5. Determining Absolute Configuration Using CEC Method:

Experiment developed from work in Rychnovsky lab. Students qualitatively and quantitatively determine which reaction proceeds faster in a matched and mismatched case of acetylation of an alcohol with a chiral catalyst and determine absolute configuration of unknown chiral alcohol. Review of assigning R/S and optical rotation included.

\section{Aldol Condensation:}

Double aldol condensation with unknown aldehyde and ketone. Differentiate aldehyde and ketone by IR spectroscopy. Determine structures of unknowns by first determining structure of product by ${ }^{1} \mathrm{H}$ and ${ }^{13} \mathrm{C}$ NMR.

8. Rate Law Determination and Visible Spectroscopy:

Visible spectroscopy is used to measure the disappearance of crystal violet as a result of hydroxylation. The rate law, rate constant, and half-life are determined. Spartan investigation of a reaction coordinate diagram.

\section{Creating Video Versions of Our Existing Experiments}

Both the GCL-I and OCL-II course teams filmed video content during spring break and the

beginning of the spring quarter while following all public health guidelines. The GCL-I videos were

filmed and edited by the development TAs, whereas the OCL-II videos were filmed and edited by the

university media team. TAs wrote the scripts and served as actors in the videos. During the editing process, videos were segmented into approximately 15 minute portions to maintain student attention and increase comprehension. ${ }^{45}$ Automatically graded Canvas video quizzes promoted student accountability and engagement. 46,47 TAs in the general chemistry videos narrated their actions in detail to guide less experienced students through the basic techniques and data collection performed. In 


\section{STRUCTURING THE REMOTE VERSIONS OF THE FIRST-TERM GENERAL CHEMISTRY AND SECOND- TERM ORGANIC LABORATORY}

\section{Scheduling}

To achieve a high structure format for the remote versions of both GCL-I and OCL-II, modifications from the in-person versions of the courses were required. Many of the structural similarities between the two courses allowed for equivalent alterations to scheduling and ELN use. The typical experiment schedule for both courses was delayed by one week to expand the time available for curriculum development and provide students with a structured introduction to the online laboratory format. In the GCL-I course, the first week of the quarter introduced students to the online tools required for the course (i.e. Zoom video conferencing tool, Piazza message boards, ELN, Canvas, Spartan computational software, and Sapling Learning online homework) through webinars. ${ }^{21,22,26,48-50}$ Because most students in the OCL-II course were already familiar with the online tools, the first week was devoted to a writing workshop in which students critiqued and revised one of their laboratory reports from a previous course. Delaying experimental work also allowed us to support the technological needs of students and TAs. Laptops with cameras were loaned to students from our teaching laboratory stockroom. Writing tablets, webcams, and smartphone holders were distributed to TAs to enable remote teaching.

For the in-person version of both courses, assignment due dates were scheduled to correlate to the day and time of a student's laboratory section. To provide a clearer course structure for students enrolled in the remote courses, the availability of weekly content and assignment due dates were made the same for all students, regardless of the day and time of their scheduled laboratory section (Figure 1). ${ }^{47,51}$ To provide additional clarity, both courses utilized the announcement function of Canvas on a weekly basis to connect due dates to assignment expectations. ${ }^{29,52}$ 


\begin{tabular}{|c|c|c|c|c|c|}
\hline Week & Monday & Tuesday & Wednesday & Thursday & Friday \\
\hline \multirow{2}{*}{3} & $\begin{array}{c}\text { GCL-I SAPLING DUE } \\
11: 59 \text { PM }\end{array}$ & $\begin{array}{c}\text { GCL-I EXP } 2 \text { VIDEO AND } \\
\text { CANVAS QUIZ OPEN } 12 \\
\text { PM }\end{array}$ & & $\begin{array}{c}\text { GCL-I EXP } 1 \text { POST LAB } \\
\text { DUE 11:59 PM }\end{array}$ & $\begin{array}{l}\text { GCL-I EXP } 2 \text { PRE/IN- } \\
\text { LAB AND CANVAS } \\
\text { QUIZ DUE 11:59 PM }\end{array}$ \\
\hline & $\begin{array}{l}\text { OCL-II EXP } 2 \text { VIDEO } \\
\text { OPEN } 10 \text { PM }\end{array}$ & $\begin{array}{c}\text { OCL-II PRE-LAB VIDEO } \\
\text { QUIZZES, SAPLING, AND } \\
\text { EXP } 2 \text { PRE-LAB DUE } 1 \\
\text { PM }\end{array}$ & & $\begin{array}{l}\text { OCL-II EXP } 1 \text { POST } \\
\text { LAB DUE 11:59 PM }\end{array}$ & $\begin{array}{l}\text { OCL-II EXP } 2 \text { IN-LAB } \\
\text { AND CANVAS QUIZ } \\
\text { DUE 11:59 PM }\end{array}$ \\
\hline \multirow{2}{*}{4} & $\begin{array}{c}\text { GCL-I SAPLING DUE } \\
11: 59 \text { PM }\end{array}$ & $\begin{array}{c}\text { GCL-I EXP } 3 \text { VIDEO AND } \\
\text { CANVAS QUIZ OPEN } 12 \\
\text { PM }\end{array}$ & & $\begin{array}{c}\text { GCL-I EXP } 2 \text { POST LAB } \\
\text { DUE 11:59 PM }\end{array}$ & $\begin{array}{l}\text { GCL-I EXP } 3 \text { PRE/IN- } \\
\text { LAB AND CANVAS } \\
\text { QUIZ DUE 11:59 PM }\end{array}$ \\
\hline & $\begin{array}{c}\text { OCL-II EXP } 3 \text { VIDEO } \\
\text { OPEN } 10 \text { PM }\end{array}$ & $\begin{array}{c}\text { OCL-II PRE-LAB VIDEO } \\
\text { QUIZZES, SAPLING, AND } \\
\text { EXP } 3 \text { PRE-LAB DUE } 1 \\
\text { PM }\end{array}$ & & $\begin{array}{l}\text { OCL-II EXP } 2 \text { POST } \\
\text { LAB DUE 11:59 PM }\end{array}$ & $\begin{array}{c}\text { OCL-II EXP } 2 \text { IN-LAB } \\
\text { AND CANVAS QUIZ } \\
\text { DUE 11:59 PM }\end{array}$ \\
\hline
\end{tabular}

Figure 1. Representative two-week schedule for GCL-I (green) and OCL-II (blue).

\section{Electronic Laboratory Notebook and Data Sets}

In previous quarters, students completed all sections of a blank ELN page weekly. To account for the lack of in-person communication this quarter, scaffolding was added to the ELN page and gradually reduced as the course progressed. In initial experiments, prefilled sections were added as examples for students to reference in later weeks when the scaffold was removed. This modification was included in both courses to ease the ELN learning curve for the new laboratory students in GCL-I and provide added direction in OCL-II.

Student ELN entries from previous iterations of the course were also leveraged to provide unique data sets to minimize academic dishonesty. These data sets were distributed to each section at the end of the Canvas video quizzes (see Supporting Information for data delivery instructions). The two instructional teams had different goals when selecting data. The general chemistry team provided "good" data that approximated ideal results to ease new students into the teaching laboratory course environment. The organic chemistry team, however, provided their more experienced students with 
imperfect data to provide opportunities for rich discussion around limitations of experiments and their outcomes.

Staff Meetings, Office Hours, and Class Meetings

Although both courses retained similar course structures, differences in enrollment and student demographics required course-specific approaches to laboratory lectures, teaching staff meetings, office hours, and online homework. Some synchronous class meetings were held for each course, although the approach to these meetings differed. During weeks when challenging concepts were introduced in GCL-I (e.g. graphing, calculations with significant figures, etc.), multiple live webinars were held to supplement instructor lecture videos. Students in OCL-II attended one 50-minute weekly, interactive laboratory lecture on Zoom. Students engaged with material using PollEverywhere to earn participation credit and communicated using Zoom's chat feature. ${ }^{53}$ The laboratory lecture was recorded and provided along with a make-up assignment on Canvas for students who could not attend. A similar online lecture format has been offered in previous years. This experience enabled us to easily shift to a fully online laboratory lecture and expand existing instructional techniques in OCLII.

Management of the TAs in both courses was handled using a weekly one-hour staff meeting on Zoom. During previous in-person meetings, a group of 3-4 TAs who performed the current week's experiment beforehand would present various procedural tips and tricks which they believed would help fellow TAs in the laboratory. For GCL-I this quarter, these TAs could not perform the experiments, so presentations focused on contextualizing the laboratory material and explaining the theory underlying the laboratory techniques and instrumentation. Because OCL-II had fewer TAs due to lower enrollment, staff meetings required less structure.

The GCL-I TAs held one, two-hour office hour weekly over Zoom in pairs. Each pair's office hours were scheduled on the same day and time as their assigned laboratory section to ensure students could meet with their designated TA. Student attendance was encouraged, but not required. More experienced TAs were strategically paired with less experienced TAs. Within the pair, one TA responded to questions by speaking while the other TA responded to questions by typing into the chat window. 
The OCL-II TAs met with students online during the first half of their regularly scheduled laboratory section and held two, one-hour office hours each week. Like GCL-I, student attendance at these scheduled meetings was encouraged, but not required. TAs began synchronous class meetings by giving a short summary of the experiment. Then TAs played the in-laboratory videos using screen share and stopped the video at strategic points to engage students in a discussion of key steps or concepts. Class meetings ended with a question and answer session. In addition to the class meeting, OCL-II TAs held two unstructured office hour meetings. Pairing TAs was unnecessary for office hours as there were fewer attendees. Office hours for the organic chemistry laboratory course were also held over Zoom using the Canvas integration. ${ }^{54}$

\section{Monitoring Online Homework}

Although both courses use online prelaboratory homework, the GCL-I team developed a computer script, titled BigBrother, to streamline TA responsibilities. In a typical academic term, TAs would log into Sapling and manually check for incomplete assignments. In GCL-I, a course with 28 TAs for 56 lab sections, BigBrother identified students with incomplete online homework and sent a student list by section directly to the appropriate TA's account in a messaging platform (Slack). ${ }^{55}$ The annotated code is provided in the Supporting Information.

\section{REPLACING THE IN-PERSON LABORATORY PRACTICAL EXAMS}

Both the GCL-I and OCL-II courses typically conclude with a practical exam. ${ }^{56-59}$ Different approaches were taken by each course to replace these exams because GCL-I uses a traditional points-based grading system, whereas OCL-II uses a specifications grading system. ${ }^{60,61}$ However, the widespread social uprising that occurred in late May and early June of 2020 in response to the deaths of Ahmaud Arbery, Breonna Taylor, George Floyd, and others necessitated alterations to our plans. Many of our students were directly impacted by the widespread protests and media reporting. We include both the intended exam replacement plans and our emergency adjustments here for clarity and discussion.

The traditional, in-person format of the GCL-I practical exam consisted of students performing two short wet-laboratory exercises taken directly from experiments conducted during the quarter, analyzing data collected from a computational study, and answering multiple-choice questions 
pertaining to safe laboratory practices. In the remote version of the course, the new exam consisted of two parts: a Canvas quiz, requiring the Respondus LockDown browser and Monitor AI, and two "takehome" essays submitted to Gradescope. ${ }^{62}$ The Canvas quiz assessed the understanding of chemical theory and data analysis. The goal of the essays was to encourage students to demonstrate conceptual understanding of two general chemistry laboratory techniques. ${ }^{63-65}$ Students selected and responded to two of six possible essay prompts. They then researched and described the procedures of their two chosen laboratory techniques in detail. A table of essay prompts, response rates, and averages can be found in the Supporting Information.

GCL-I final exams began Monday, June 1, 2020. However, campus guidance for changes to final examinations was announced two days later as administrators attempted to respond to the evolving social uprising and its impacts on our students. Because the exams had already started for about half of the 1,403 students, the alteration of exam content or conditions could be perceived as unfair by those who had already taken the exam. However, students needing accommodations throughout the week were allowed to take the online exam or turn in the essays at later dates.

The in-person final exam structure for OCL-II consisted of three required assignments for all students to earn passing grades and additional assessments to achieve an A or B letter grade. The initial plan for final assessments in this remote format retained all of the in-person components with two adjustments. Two of the mandatory assessments, a safety exam and an exam covering concepts and data analysis, would be administered as automatically graded Canvas quizzes. These quizzes were intended to evaluate understanding of laboratory safety and overall understanding of course content. A third mandatory assessment on thin layer chromatography would be converted from a hands-on activity to an online quiz using both Canvas and Chemix, a chemistry diagramming software. ${ }^{66}$

To earn more than a passing grade in the course, students would have completed additional technique assessments using Canvas and Chemix on liquid-liquid extraction and recrystallization (Figure 2). Students would also have completed a mastery project where they develop a hypothesis and analyze experimental data related to a previously studied reaction. The project, designed to replace open-ended questions on typical practical exams, could either be presented as a lab report for a B grade or as a journal-style article or research poster for an A grade.67,68 


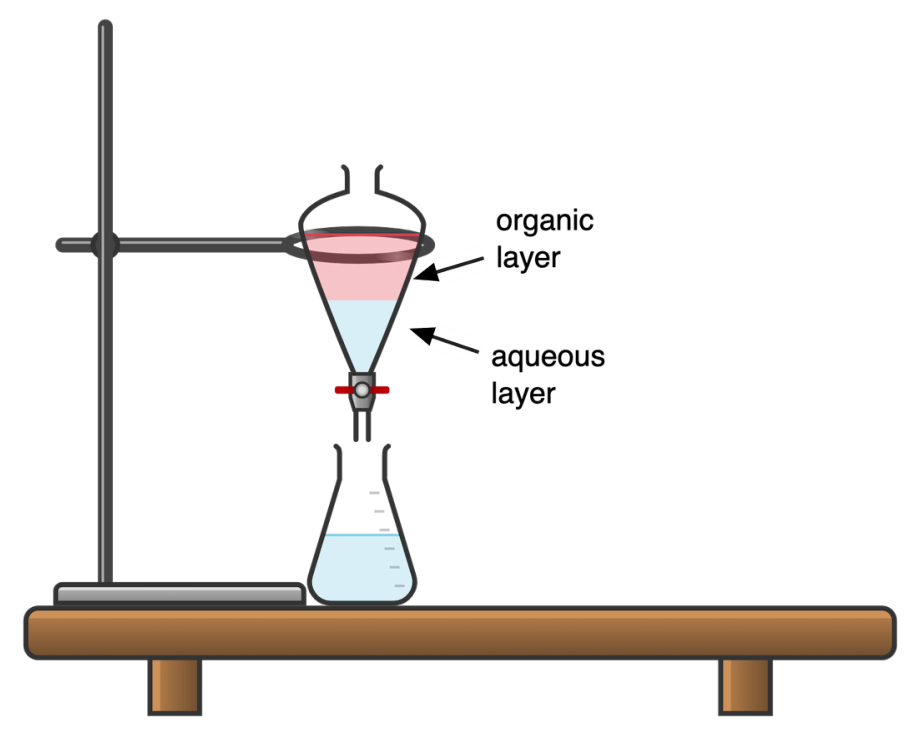

Figure 2. Chemix drawing of liquid-liquid extraction.

Although we created a comprehensive set of exam replacements, the social upheaval that impacted our students necessitated a rapid change in plans. The following adjustments were made to the final examination for the organic chemistry laboratory: technique tests required for A and B grades were already completed, but the remainder of the planned assessments were cancelled. A set of alternative assignments were introduced. All students chose from one of the three following options: 1) complete the mastery project they had already started, 2) write advice to students attempting to study during times of great trauma, or 3) create a multimedia presentation of their choice connecting chemistry to something they were experiencing. All three assessment options were graded on a complete/incomplete basis with credit awarded for any good faith effort. Students appreciated the accommodations, and several welcomed them as a safe space to express their struggles in dealing with traumatic experiences.

\section{STUDENT AND TA FEEDBACK}

Surveys were administered to determine how students and TAs perceived the remote course structure. The GCL-I team administered two surveys: a mid-quarter and a post-quarter. Of the 1,403 students and 28 TAs in the GCL-I course, 79\% of students and 64\% of TAs responded to the midquarter survey, respectively (Table 4). A total of $67 \%$ of students and $82 \%$ of TAs completed the postquarter survey. The OCL-II team administered one student survey late in the quarter. Of the 104 students in the OCL-II course, $84 \%$ of students responded. Because this survey was completed later in 
the quarter than the corresponding survey in the GCL-I course, a final student survey was not conducted. Informal feedback was collected from TAs weekly, and a TA survey was conducted at the conclusion of the term. Survey questions are included in the Supporting Information.

Table 4. Feedback collection methods and response rates for remote delivery GCL-I and OCL-II.

\begin{tabular}{lll|}
\hline Feedback Collection & \multicolumn{1}{c|}{ GCL-I Response Rate } & OCL-II Response Rate \\
Student mid-quarter & $1,101(79 \%)$ & $87(84 \%)$ \\
& & \\
TA mid-quarter* & $18(64 \%)$ & $4(100 \%)$ \\
Student post-quarter & $943(67 \%)$ & NA \\
TA post-quarter & $23(82 \%)$ & $4(100 \%)$ \\
\hline
\end{tabular}

${ }^{*}$ Feedback from OCL-II TAs was solicited through conversations in weekly staff meetings. Students: $\mathrm{N}=1,403$ for GCL-1, N = 104 for OCL-II, TAs: $\mathrm{N}=28$ for GCL-I, $\mathrm{N}=4$ for OCL-II.

\section{GCL-I Student Feedback}

Student responses to the mid-quarter and post-quarter surveys were mostly positive. Students valued Canvas, citing its modular set-up and summary of assignment due dates. They also appreciated the video demonstrations of the experiments and taking associated quizzes. Perceptions of the ELN and Piazza in the mid-quarter survey were mixed. Actions were taken to address these concerns and post-quarter survey responses indicated the changes made were well received.

While students liked the scaffolding of the ELN, they wanted more direction for its use. We subsequently recorded an instructional video describing the use of the ELN functionalities, especially how to properly download and submit the page for grading to aid students navigating the ELN for the first time. ${ }^{69,70}$ Students also expressed frustration and anxiety about the time consuming nature of filling out the ELN, a sentiment which is not unique to this remote course. Students are often surprised by the workload in their first laboratory course. The instructor and two development TAs filmed short videos addressing these and other student concerns from the mid-quarter survey which was intended to enhance student perceptions of instructor presence in the course. ${ }^{18,40}$

Students also identified the Piazza message board as a source of anxiety. The number of message board posts was ten times higher than the previous year (Table 5). Many students felt they needed to 
read all responses to ensure understanding of assignment expectations. Conversely, the redundant questions indicated many other students were not reviewing answered posts before making their own. This behavior was partially encouraged by a faster average response time compared to the prior year.

\section{Table 5. GCL-I Piazza Statistics for $2019 \& 2020$}

\begin{tabular}{lll}
\hline Comparison of In-Person \& Remote Instruction & Spring 2019 & Spring 2020 \\
Questions asked & 903 & 7,131 \\
Posts, responses, edits, follow ups, comments & 2,615 & 29,806 \\
Average response time & 33 minutes & 6 minutes \\
Percentage of students with at least one contribution & $32 \%$ & $62 \%$ \\
\hline
\end{tabular}

To reduce the number of posts and student anxiety, many question-by-question responses were curtailed. The most commonly asked questions each week were compiled and answered in a single announcement. This reduced the overall number of posts and provided the TAs with a set of talking points to address during office hours. Immediately following the first announcement, the number of posts was almost cut in half, but the number of users (viewers) remained very high (Figure 3). ${ }^{71,72} \mathrm{In}$ the final course survey, students indicated the changes to Piazza reduced anxiety by making answers easy to find.

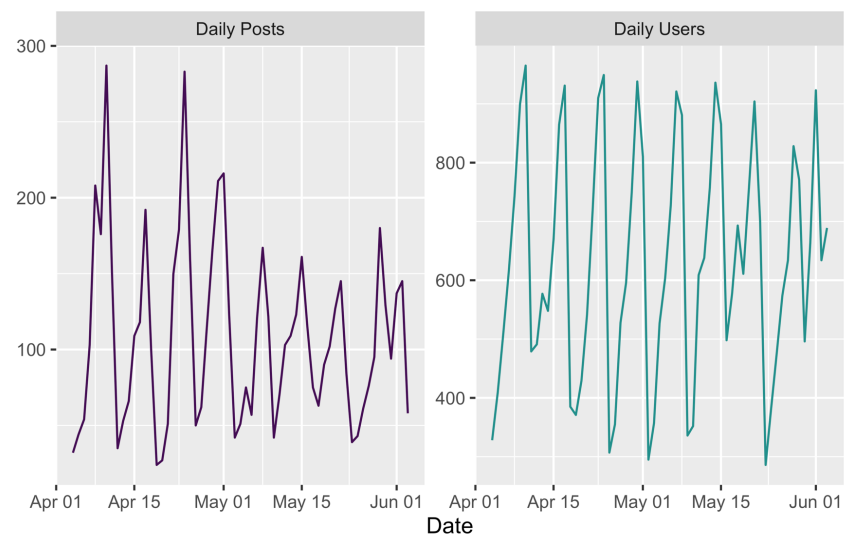

Figure 3. GCL-I Remote Instruction Piazza Messageboard Users and Posts 


\section{GLC-I TA Feedback}

GCL-I TAs overwhelmingly agreed that the most positive moments they experienced with students were running office hours through Zoom. TAs noted having a partner to split work between vocal and written (chat) response was an optimal arrangement. However, TAs did indicate occasional difficulty fielding a large volume of student questions through the chat function. TAs appreciated the ability to screen share to guide students through online tools and subject matter questions. They also noted the regular attendance of a sizable number of motivated students, in contrast to much lower attendance of typically 5-10 students for in-person office hours in previous quarters. Weekly attendance at each office hour started at over 100 students on average and then dropped to about 25 students toward the end of the quarter (Figure 4). While TAs commented positively about the use of Zoom, they also voiced concerns about the lack of connection to their students because of the absence of face-to-face contact.

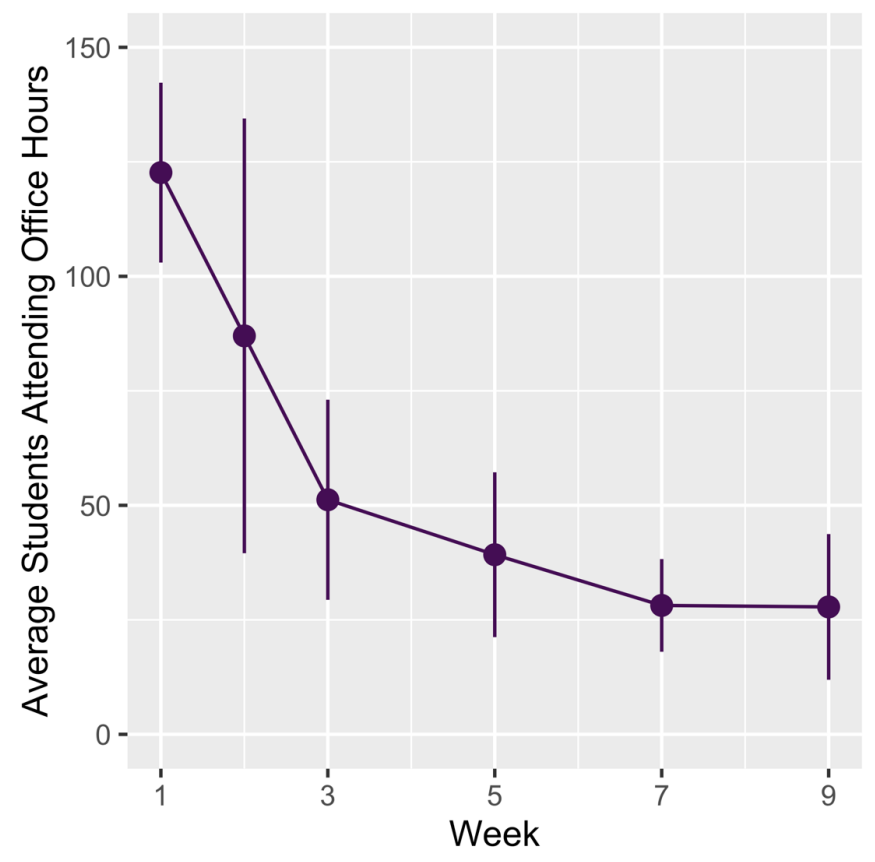

Figure 4. Average GCL-I office hour attendance by week. Error bars are \pm standard deviation.

The changes to in-person staff meetings that were adopted for the remote setting were described by TAs as insufficient preparation for teaching during office hours. Most of the student questions pertained to assignment rubrics and grading rather than the theory underlying the laboratory 
techniques and instrumentation. TAs expressed that going over the rubrics during the staff meeting would be better preparation for their office hours. This change was made following the mid-quarter survey and was received positively based on TA responses to the post-quarter survey. TAs voiced that the change lessened the time spent on grading overall so it was easier to meet the weekly grading deadlines set by the instructor. TAs also unanimously praised the integration of the BigBrother code with Sapling and Slack, commenting that the code lightened their workload because it simplified checking the Sapling prelaboratory requirements, which was done manually in previous quarters.

\section{OCL-II Student Feedback}

Students in OCL-II were surveyed once in the latter part of the term before final exams. No immediate course changes were made because the survey was administered after the final experiment week concluded. We planned a post-course survey to gather student feedback on the exam components, but this survey was abandoned when exams were cancelled. When asked what they liked best about the online lab sections, many students remarked they could more easily ask questions in this format. Students attributed this difference to greater ease of getting the TA's attention and a lack of time pressure to complete laboratory work. Many students valued watching the videos together with their TA and classmates. However, they suggested that the TAs should have more structure in guiding the class discussion around what was happening in the experiment videos. Students appreciated the overall structure and organization of the course, especially the consistent weekly deadlines. Most comments on improvement for the course organization addressed issues of Canvas structure that cannot be altered. Students felt that the lab lecture component of the course was helpful, and those who had experienced the in-person laboratory lecture in previous courses thought the online version was similar. Based on student comments, we succeeded in establishing a sense of connection between the students and the instructors in this new course format, but many students felt disconnected from their classmates in the online environment.

\section{OCL-II TA Feedback}

At the conclusion of the course, the OCL-II TAs completed a survey comparing the remote teaching experience to their prior in person experience. TAs felt that the remote lab required a smaller time commitment due to the lack of in-person, four-hour lab periods. An average of 13 students attended 
weekly "in-lab" meetings where TAs led viewing and discussion of the video with students, and office hours attendance was less than for in-person courses they had taught previously. Typically, students needed more guidance when interpreting data and performing error analysis as compared to TAs' previous experiences.

OCL-II TAs also commented on some of the benefits and challenges associated with remote learning. TAs cited an increased focus during the remote "in-lab" meetings on theory and concepts associated with the experiment in comparison with prior in-person teaching experiences. This change may have resulted from a decreased cognitive load required to watch experiment videos instead carrying out experimental procedures. ${ }^{73,74}$ The increased flexibility of the online format also allowed students to contact their TAs more easily compared to attending in-person office hours. In contrast, TAs felt the biggest challenges, aside from lack of hands-on experience, were associated with TAstudent interactions. Although some students were more engaged, this was not true for all students. TAs perceived an overall decrease in student participation and struggled to assess the gaps in students' knowledge.

\section{LESSONS LEARNED AND PLANNED CHANGES FOR FUTURE ITERATIONS}

Despite the limited time frame to enact our emergency pivot to a new remote delivery environment for the GCL-I and OCL-II courses, the students and instructional teams for both courses felt the endeavor was a success. The positive student response to our emergency remote laboratory courses will inform the creation of additional laboratory courses while the global pandemic necessitates continued remote learning. Future courses, currently in development, will retain the same overall structure, consistent due dates, and synchronous class meetings with asynchronous options for students experiencing scheduling challenges.

The instructional teams of the general and organic chemistry laboratories historically have worked together, adopting many of the same web-based tools that served us well during this pandemic. Our similar approaches allow us to address the challenges we encountered during the first quarter of remote instruction in ways that will improve future iterations of both laboratory series. Based on the GCL-I team's experience, staff meetings will be restructured to help TAs focus on student needs in the remote delivery of the course. Because the experimental videos are now complete, TAs will be required 
to watch the experiment video and fill out an electronic survey before each meeting. This survey will have two goals: (1) to actively engage the TAs in video experiments and, (2) to generate talking points for office hours with students. A group of TAs will also be assigned to lead a discussion of the survey responses and rubrics for the experiment running that week. All large-scale courses will manage message boards with daily instructor posts. Because course content has now been prepared, we plan to open modules earlier in each term to allow students greater flexibility in managing their weekly workload. Finally, we endeavor to create more connections between students during Zoom lab sessions by strategically employing tools such as polling and emoticon use to encourage full participation, using the new Live Chat function in Piazza to structure discussion, and instituting group work where applicable in break out rooms. ${ }^{75-78}$

Regardless of the successes we have had in creating online laboratory courses, we still strongly assert that this emergency replacement does not meet the primary objective of any laboratory course - performing fundamental laboratory techniques. To enhance all aspects of learning chemistry, hands-on interaction with chemicals and laboratory instruments are essential. ${ }^{3}$ While we were able to challenge our students with assignments that required conceptual understanding and critical analysis, we could not assess their ability to manipulate laboratory glassware or use laboratory instrumentation. ${ }^{5}$ We look forward to the return of in-person laboratory courses.

\section{ASSOCIATED CONTENT}

Supporting Information

Survey Information and Instructor Resources (PDF)

BigBrother Python Code (TXT)

\section{AUTHOR INFORMATION}

Corresponding Author

*E-mail: $\underline{\text { kdmullen@uci.edu }}$

Author Contributions

\#W.J.H., T.A.T., T.L.F, X.R.S contributed equally.

\section{NOTES}

The authors declare no competing financial interests. 


\section{ACKNOWLEDGMENTS}

We thank the University of California, Irvine Chemistry department for their support and resources

during this endeavor. We thank our TAs, Charles Kysor, Natalie Minnetian, and Yash Gargasya, and our LAs, Karen Vega and Ishan Shah, for their contributions to the GCL-I development team. We also thank Mike Tran for his support with purchasing equipment needed to film the GCL-I experiment videos. We thank the OCL-II TAs, Bryant Lim and Amanda Chung, and peer tutors, Aneesah Akbar and Yasmeen Fazeli, for their contributions to the OCL-II development team. We also thank the UCI media team who filmed the experiment videos for OCL-II. Without their help, this transition to online laboratories would be impossible. We also thank our laboratory TAs and their students for adapting quickly and professionally to the unfamiliar online environment. Additionally, we thank the makers of Chemix for working with the OCL-II team to generate new features in their product to support online learning. Lastly, we thank Cassandra Triggs for creating our abstract graphic, and we thank ChemTwitter for acting as a sounding board and invaluable resource during this challenging time.

\section{REFERENCES}

(1) Coronavirus disease (COVID-19) pandemic https://www.who.int/emergencies/diseases/novelcoronavirus-2019 (accessed Jun 12, 2020).

(2) Chemistry majors have a separate series of laboratory courses not discussed here.

(3) Importance of Hands-on Laboratory Science - American Chemical Society https://www.acs.org/content/acs/en/policy/publicpolicies/education/computersimulations.html (accessed Jun 23, 2020).

(4) Committee on Professional Training. Adjusted ACS Guidelines for Approved Programs: A Response to COVID-19; American Chemical Society, 2020.

(5) Reeves, J. H.; Exton, D. Developing the First Online General Chemistry Laboratory Exam. In Innovative Uses of Assessments for Teaching and Research; ACS Symposium Series; American Chemical Society: Washington, DC, 2014; Vol. 1182, pp 181-191.

(6) Khan, S. The Future of Computer Simulations Designed for Classroom Instruction. In Pedagogic Roles of Animations and Simulations in Chemistry Courses; ACS Symposium Series; American Chemical Society: Washington, DC, 2013; Vol. 1142, pp 341-365.

(7) Pölloth, B.; Teikmane, I.; Schwarzer, S.; Zipse, H. Development of a Modular Online Video Library for the Introductory Organic Chemistry Laboratory. J. Chem. Educ. 2020, 97 (2), 338-343. 
(8) Cresswell, S. L.; Loughlin, W. A.; Coster, M. J.; Green, D. M. Development and Production of Interactive Videos for Teaching Chemical Techniques during Laboratory Sessions. J. Chem. Educ. 2019, 96 (5), 1033-1036.

(9) Jordan, J. T.; Box, M. C.; Eguren, K. E.; Parker, T. A.; Saraldi-Gallardo, V. M.; Wolfe, M. I.; Gallardo-Williams, M. T. Effectiveness of Student-Generated Video as a Teaching Tool for an Instrumental Technique in the Organic Chemistry Laboratory. J. Chem. Educ. 2016, 93 (1), 141145.

(10) Agustian, H. Y.; Seery, M. K. Reasserting the Role of Pre-Laboratory Activities in Chemistry Education: A Proposed Framework for Their Design. Chem. Educ. Res. Pract. 2017, 18 (4), 518532.

(11) He, Y.; Swenson, S.; Lents, N. Online Video Tutorials Increase Learning of Difficult Concepts in an Undergraduate Analytical Chemistry Course. J. Chem. Educ. 2012, 89 (9), 1128-1132.

(12) Stieff, M.; Werner, S. M.; Fink, B.; Meador, D. Online Prelaboratory Videos Improve Student Performance in the General Chemistry Laboratory. J. Chem. Educ. 2018, 95 (8), 1260-1266.

(13) Veiga, N.; Luzardo, F.; Irving, K.; Rodríguez-Ayán, M. N.; Torres, J. Online Pre-Laboratory Tools for First-Year Undergraduate Chemistry Course in Uruguay: Student Preferences and Implications on Student Performance. Chem. Educ. Res. Pract. 2019, 20 (1), 229-245.

(14) Rudolphi, F.; Goossen, L. J. Electronic Laboratory Notebook: The Academic Point of View. J. Chem. Inf. Model. 2012, 52 (2), 293-301.

(15) Bromfield Lee, D. Implementation and Student Perceptions on Google Docs as an Electronic Laboratory Notebook in Organic Chemistry. J. Chem. Educ. 2018, 95 (7), 1102-1111.

(16) Van Dyke, A. R.; Smith-Carpenter, J. Bring Your Own Device: A Digital Notebook for Undergraduate Biochemistry Laboratory Using a Free, Cross-Platform Application. J. Chem. Educ. 2017, 94 (5), 656-661.

(17) Dood, A. J.; Johnson, L. M.; Shorb, J. M. Electronic Laboratory Notebooks Allow for Modifications in a General, Organic, and Biochemistry Chemistry Laboratory To Increase Authenticity of the Student Experience. J. Chem. Educ. 2018, 95 (11), 1922-1928.

(18) Draus, P. J.; Curran, M. J.; Trempus, M. S. The Influence of Instructor-Generated Video Content on Student Satisfaction with and Engagement in Asynchronous Online Classes. J. Online Learn. Teach. 2014, 10 (2), 240-254. 
(19) Rose, K. K. Student Perceptions of the Use of Instructor-Made Videos in Online and Face-to-Face Classes. MERLOT Journal of Online Learning and Teaching 2009, 5 (3), 487-495.

(20) Martin, F.; Wang, C.; Sadaf, A. Student Perception of Helpfulness of Facilitation Strategies That Enhance Instructor Presence, Connectedness, Engagement and Learning in Online Courses. The Internet and Higher Education 2018, 37, 52-65.

(21) LabArchives https://www.labarchives.com/ (accessed Jun 23, 2020).

(22) Higher Education e-Learning Platform | Canvas | Instructure https://www.instructure.com/canvas/higher-education (accessed Jun 23, 2020).

(23) Chittleborough, G. D.; Treagust, D. F.; Mocerino, M. Achieving Greater Feedback and Flexibility Using Online Pre-Laboratory Exercises with Non-Major Chemistry Students. J. Chem. Educ. 2007, 84 (5), 884.

(24) Parker, L. L.; Loudon, G. M. Case Study Using Online Homework in Undergraduate Organic Chemistry: Results and Student Attitudes. J. Chem. Educ. 2013, 90 (1), 37-44.

(25) Gradescope | Save time grading https://www.gradescope.com/ (accessed Jun 23, 2020).

(26) Piazza • Ask. Answer. Explore. Whenever https://piazza.com/ (accessed Jun 23, 2020).

(27) Behmke, D. A.; Atwood, C. H. IM-Chem: The Use of Instant Messaging To Improve Student Performance and Personalize Large Lecture General Chemistry Courses. J. Chem. Educ. 2012, 89 (4), 474-476.

(28) Eskey, M. T.; Schulte, M. What Online College Students Say about Online Instructors and What Do Online Faculty Members Say about Online Instruction: A Comparison of Attitudes. Journal of Online Education 2010, 1-20.

(29) Sheridan, K.; Kelly, M. A. The Indicators of Instructor Presence That Are Important to Students in Online Courses. MERLOT Journal of Online Learning and Teaching 2010, 6 (4), 767-779.

(30) Haak, D. C.; HilleRisLambers, J.; Pitre, E.; Freeman, S. Increased Structure and Active Learning Reduce the Achievement Gap in Introductory Biology. Science 2011, 332 (6034), 1213-1216.

(31) Freeman, S.; Haak, D.; Wenderoth, M. P. Increased Course Structure Improves Performance in Introductory Biology. CBE Life Sci. Educ. 2011, 10 (2), 175-186.

(32) Eddy, S. L.; Hogan, K. A. Getting under the Hood: How and for Whom Does Increasing Course Structure Work? CBE Life Sci. Educ. 2014, 13 (3), 453-468.

(33) He, W.; Holton, A.; Farkas, G.; Warschauer, M. The Effects of Flipped Instruction on out-of-Class Study Time, Exam Performance, and Student Perceptions. Learn Instr 2016, 45, 61-71. 
(34) Crimmins, M. T.; Midkiff, B. High Structure Active Learning Pedagogy for the Teaching of Organic Chemistry: Assessing the Impact on Academic Outcomes. J. Chem. Educ. 2017, 94 (4), 429-438.

(35) He, W.; Holton, A. J.; Farkas, G. Impact of Partially Flipped Instruction on Immediate and Subsequent Course Performance in a Large Undergraduate Chemistry Course. Comput. Educ. 2018, 125, 120-131.

(36) Wilton, M.; Gonzalez-Niño, E.; McPartlan, P.; Terner, Z.; Christoffersen, R. E.; Rothman, J. H. Improving Academic Performance, Belonging, and Retention through Increasing Structure of an Introductory Biology Course. CBE Life Sci. Educ. 2019, 18 (4), ar53.

(37) Gavassa, S.; Benabentos, R.; Kravec, M.; Collins, T.; Eddy, S. Closing the Achievement Gap in a Large Introductory Course by Balancing Reduced In-Person Contact with Increased Course Structure. CBE Life Sci. Educ. 2019, 18 (1), 1-10.

(38) Garrison, D. R.; Anderson, T.; Archer, W. Critical Inquiry in a Text-Based Environment: Computer Conferencing in Higher Education. The Internet and Higher Education 1999, 2 (2), 87105.

(39) Deacon, A. Creating a Context of Care in the Online Classroom. The Journal of Faculty Development 2012, 26 (1), 5.

(40) Ladyshewsky, R. K. Instructor Presence in Online Courses and Student Satisfaction. International Journal for the Scholarship of Teaching and Learning 2013, 7 (1), 13.

(41) Darby, F.; Lang, J. M. Small Teaching Online: Applying Learning Science in Online Classes, 1 edition.; Jossey-Bass: San Francisco, 2019.

(42) Carrigan, K. Review of LabPaq Science Lab Kits for Chemistry. J. Chem. Educ. 2012, 89 (3), 314-315.

(43) Dunnagan, C. L.; Dannenberg, D. A.; Cuales, M. P.; Earnest, A. D.; Gurnsey, R. M.; GallardoWilliams, M. T. Production and Evaluation of a Realistic Immersive Virtual Reality Organic Chemistry Laboratory Experience: Infrared Spectroscopy. J. Chem. Educ. 2019.

(44) Beyond Labz https://www.beyondlabz.com/ (accessed Jun 12, 2020).

(45) Brame, C. J. Effective Educational Videos: Principles and Guidelines for Maximizing Student Learning from Video Content. CBE Life Sci. Educ. 2016, 15 (4).

(46) Pape-Lindstrom, P.; Eddy, S.; Freeman, S. Reading Quizzes Improve Exam Scores for Community College Students. CBE Life Sci. Educ. 2018, 17 (2), ar21. 
(47) Memory. In Minds Online: Teaching Effectively with Technology; Miller, M. D., Ed.; Harvard University Press: Cambridge, MA, 2014; pp 88-116.

(48) Video Conferencing, Web Conferencing, Webinars, Screen Sharing https://zoom.us/ (accessed Jun $23,2020)$.

(49) Spartan Software http://ww2.wavefun.com/products/spartan.html (accessed Jun 23, 2020).

(50) Sapling Learning \& SaplingPlus | Macmillan Learning for Instructors https://www.macmillanlearning.com/college/us/digital/sapling (accessed Jun 23, 2020).

(51) Swan, K.; Shea, P.; Fredericksen, E.; Pickett, A.; Pelz, W.; Maher, G. Building Knowledge Building Communities: Consistency, Contact and Communication in the Virtual Classroom. Journal of Educational Computing Research 2000, 23 (4), 359-383.

(52) Summers, J. J.; Waigandt, A.; Whittaker, T. A. A Comparison of Student Achievement and Satisfaction in an Online Versus a Traditional Face-to-Face Statistics Class. Innovative Higher Education 2005, 29 (3), 233-250.

(53) Host interactive online meetings | Poll Everywhere https://www.polleverywhere.com/ (accessed Jun 23, 2020).

(54) The Canvas-Zoom integration fails in a course with more than ten instructors, so this integration was not used in the larger GCL-I course.

(55) Slack. Where work happens https://slack.com/ (accessed Jul 21, 2020).

(56) Hayes, D. A Laboratory Practical for a First-Semester Chemistry Course. J. Chem. Educ. 1972, 49 (10), 710 .

(57) King, M. M. A Practical Laboratory Examination for Organic Chemistry. J. Chem. Educ. 1974, 51 (2), 125.

(58) Neeland, E. G. A One-Hour Practical Lab Exam for Organic Chemistry. J. Chem. Educ. 2007, 84 (9), 1453.

(59) Hancock, L. M.; Hollamby, M. J. Assessing the Practical Skills of Undergraduates: The Evolution of a Station-Based Practical Exam. J. Chem. Educ. 2020, 97 (4), 972-979.

(60) Nilson, L. B.; Stanny, C. J. Specifications Grading: Restoring Rigor, Motivating Students, and Saving Faculty Time, Reprint edition.; Stylus Publishing: Sterling, VA, 2014.

(61) A manuscript describing the specifications grading system employed in the organic chemistry laboratory courses is currently under review. A preprint is available on ChemRxiv at https://chemrxiv.org/articles/https://doi.org/10.26434/chemrxiv.12276701.v1/12276701/1 
(62) Solutions for Higher Ed - Respondus https://web.respondus.com/he/ (accessed Jun 23, 2020).

(63) Reynolds, J. A.; Thaiss, C.; Katkin, W.; Thompson, R. J., Jr. Writing-to-Learn in Undergraduate Science Education: A Community-Based, Conceptually Driven Approach. CBE Life Sci. Educ. 2012, $11(1), 17-25$.

(64) Glynn, S. M.; Muth, K. D. Reading and Writing to Learn Science: Achieving Scientific Literacy. J. Res. Sci. Teach. 1994, 31 (9), 1057-1073.

(65) Graham, S.; Kiuhara, S. A.; MacKay, M. The Effects of Writing on Learning in Science, Social Studies, and Mathematics: A Meta-Analysis. Rev. Educ. Res. 2020, 90 (2), 179-226.

(66) Chemix https://chemix.org/ (accessed Jun 12, 2020).

(67) Schmitt, A. A.; Parise, J. A. Introducing Scientific Writing in a Second Semester Organic Chemistry Laboratory Course. In Advances in Teaching Organic Chemistry; ACS Symposium Series; American Chemical Society: Washington, DC, 2012; Vol. 1108, pp 51-71.

(68) Marino, R.; Clarkson, S.; Mills, P. A.; Sweeney, W. V.; DeMeo, S. Using Poster Sessions as an Alternative to Written Examination-The Poster Exam. J. Chem. Educ. 2000, 77 (9), 1158.

(69) Wang, F.; Lockee, B. B. Virtual Worlds in Distance Education: A Content Analysis Study. Quarterly Review of Distance Education 2010, 11 (3), 183-186.

(70) Wang, S.-K.; Hsu, H.-Y.; Campbell, T.; Coster, D. C.; Longhurst, M. An Investigation of Middle School Science Teachers and Students Use of Technology inside and outside of Classrooms: Considering Whether Digital Natives Are More Technology Savvy than Their Teachers. Educ.

(71) R Core Team. R: A Language and Environment for Statistical Computing; R Foundation for Statistical Computing: Vienna, Austria, 2019.

(72) Wickham, H.; Averick, M.; Bryan, J.; Chang, W.; McGowan, L.; François, R.; Grolemund, G.; Hayes, A.; Henry, L.; Hester, J.; Kuhn, M.; Pedersen, T.; Miller, E.; Bache, S.; Müller, K.; Ooms, J.; Robinson, D.; Seidel, D.; Spinu, V.; Takahashi, K.; Vaughan, D.; Wilke, C.; Woo, K.; Yutani, H. Welcome to the Tidyverse. JOSS 2019, 4 (43), 1686.

(73) Josephsen, J.; Kristensen, A. K. Simulation of Laboratory Assignments to Support Students' Learning of Introductory Inorganic Chemistry. Chem. Educ. Res. Pract. 2006, 7 (4), 266-279.

(74) Christiansen, M. A.; Lambert, A. M.; Nadelson, L. S.; Dupree, K. M.; Kingsford, T. A. In-Class

Versus At-Home Quizzes: Which Is Better? A Flipped Learning Study in a Two-Site Synchronously Broadcast Organic Chemistry Course. J. Chem. Educ. 2017, 94 (2), 157-163. 
(75) Gunawardena, C. N.; Zittle, F. J. Social Presence as a Predictor of Satisfaction within a Computermediated Conferencing Environment. Am. J. Distance Educ. 1997, 11 (3), 8-26.

(76) Richardson, J.; Swan, K. Examining Social Presence in Online Courses in Relation to Students' Perceived Learning and Satisfaction. Journal of Asynchronous Learning Networks 2003, 7 (1), 6888.

(77) Wei, C.-W.; Chen, N.-S.; Kinshuk. A Model for Social Presence in Online Classrooms. Educ. Technol. Res. Dev. 2012, 60 (3).

(78) Siemens, G. Connectivism: A Learning Theory for the Digital Age. International Journal of Instructional Technology and Distance Learning 2005, 2 (1). 